\title{
Moral Responsibility of State in Case of Vaccine Health Impairment
}

\author{
Barbara Preložnjak \\ University of Zagreb, Faculty of Law
}

Received 8 July 2018 - Revised 25 August 2018 • Accepted 30 September 2018

\begin{abstract}
Health is considered a fundamental human right that also has moral implication as pathological health conditions could bring comparative disadvantages among people and change their life opportunity range. Vaccination is one of the health care measures that state usually prescribes as mandatory in order to protect public health. However, vaccines can have side effects and cause, although in rare cases, health impairment that negatively effects on life opportunities. In such cases, the question is on whom lies the burden of responsibility for health impairment. In this paper, author expresses the view that it is not clear whether we can justifiably assign moral responsibility in case of vaccine health infringement to state that, in the first place, prescribes to its citizens' obligation regarding vaccination. In order to examine whether we can assign the burden of responsibility to state in the case of mandatory vaccination, we analyse moral agency, causal relevancy and opportunity of avoiding as presumptions of moral responsibility.
\end{abstract}

Keywords: right to health, vaccination, moral responsibility, causal relevancy, avoidance.

\section{Introduction}

The enjoyment of the highest attainable standard of health is considered as fundamental human right. The legal basis for the right to health is found within international law and agreements (Universal Declaration of Human Rights, 217 A (III) (1848); Universal Declaration on the Human Genome and Human Rights (1997); International Covenant on Economic, Social and Cultural Rights (1966); Kingston, Cohen \& Morley, 2010: 2). However, human rights to health have also moral implication. The moral significance of the health stem from its impact on human life, while pathological health conditions could bring comparative disadvantages among people and change their life opportunity range (Schramme, 2009: 17). If we consider vaccines, they have made an enormous contribution to public health by ensuring strong collective immunity against diseases (Greenwood, 2014: 1). Although vaccines protect health, they can cause serious side effects, which may result with health impairment (Jefferson, 1998: 159160). Health impairment certainly brings comparative disadvantages among people as it negatively effect on their life opportunities. In such cases, the question is on whom lies the burden of responsibility for health impairment. If we assume that health impairment is due to persons own choice, people are usually hesitant that society is resolving such disadvantages (Schramme, 2009: 18).

(C) Authors. Terms and conditions of Creative Commons Attribution 4.0 International (CC BY 4.0) apply. Correspondence: Barbara Preložnjak, Ph.D., Assistant Professor, Department for Legal Theory, Faculty of Law, University of Zagreb, CROATIA. E-mail: barbara.preloznjak@pravo.hr. 
For instance, if someone ruins his health by vaccines that were not mandatory, we are presuming that the person willingly chooses to receive a vaccine that resulted with health impairment. Therefore, we usually hold that person responsible for health impairment and accept that he will have to resolve all disadvantages on his own. However, if person ends up in a situation, which causes or involves health impairment and he is not accountable for plight, we are normally prepared that those who are responsible for plight undone its negative effect in order to uphold fair terms of interaction (Ripstein, 2001: 264).

- The enjoyment of the highest attainable standard of health is a fundamental human right.

- The human right to health have also moral implication.

- The state have a moral responsibility to protect its citizens from communicable diseases.

- The state should also have a moral responsibility for all losses of individual vaccine health impairment.

- Justification of a state blame calls upon the fulfillment of three conditions.

In case of mandatory vaccination, state prescribes to its citizens' obligation to receive certain vaccines in order to protect public health from communicable diseases. If the person who receives the vaccine suffers from vaccine side effects, the burden of responsibility for health harm should be held in common. That means that the state should take a risk of vaccine damages having in mind a reasonable term of cooperation among citizens, which require to "treat citizens as equals by giving each the wherewithal to choose his or her own ends, while protecting each from the excessive burdens that the choices of others might create" (Ripstein, 2001: 267). Further, if we accept that the state have a moral responsibility to protect its citizens from communicable diseases as external threats to public health, the state should also have a moral responsibility for all losses of individual vaccine health impairment as protection of individual benefits public health as well. Although moral responsibility in case of vaccine health infringement seems at times to be appropriate, it is not clear whether we can justifiably blame the state. In order to find proper answer we will assume that justification of a state blame calls upon the fulfilment of three conditions: moral agency, causal relevancy and opportunity of avoiding (Braham \& van Hees, 2012: 604). Therefore, in next chapters those conditions will be analysed in order to answer a question whether we can assign moral blame to state in the case of health impairment caused by vaccination.

\section{Moral agency of state}

The moral agency is associated with the idea of being capable of doing something that counts as a moral act. It means that one must have ability to perform actions that could be guided by and evaluated under moral standards (Himma, 2009: 21). On the other hand, to have ability to perform moral acts one must have "the capacity of making free choices, deliberating about what ought to do, and to understand and apply moral rules correctly" (Himma, 2009: 24). Most adult humans satisfy the requirements for moral agency, as they are able to understand and reflect upon moral requirements (Erskine, 2003: 21). However, moral agency should not be the characteristic of adult humans alone. Institutions, such as states, should also be able to be moral agents. If we take an example of health as morally valuable good, we are all aware that adult humans are responsible for the quality of their health. It means that they have the freedom to perform actions regarding their health protection, according to their moral judgments based on some notion of health hazardous behaviour. In case of voluntary vaccination program, one can freely make a decision not to vaccinate himself. If one catches a disease, he will be morally responsible for all negative consequences that non vaccination brought to his health or health of others in case of disease transmission. On the other hand, health is needed for minimally decent human existence and state should have an important role in protecting the health of its citizens in order to fulfil obligations, which possesses in virtue of being state (Miller, 2007: 182; Lammer-Heindel, 2012: 2). However, the question is whether the state can perform moral actions with all capacities 
needed for moral agency. According to French (1984: 29-30), it is possible to acknowledge moral agency to state. French claims that it is possible only if we presume that state is a conglomerate collectivity with an identity that do not depend on its memberships and has corporate internal decision structures. Such perception of state enables that identity of the state remains the same despite the changes in its membership while corporate internal decision structures allows the state to deliberate and to combine the intentions of individuals into corporate intentions (French, 1984: 47-48). This particularly means that the state is able through its executive and legislative organs to understand and reflect upon moral rules, as well as to act freely in a way to conform to these rules (Erskine, 2003: 69; French, 1984: 29-30; Goodin, 1995: 35-36). In order to do so, bureaucracies collect detailed and comprehensive information needed for making morally relevant decisions, to identify information systematically and to forecast the results of alternative scenarios in order to enact them as national policies (O’Neill, 1986: 62-63). Despite the fact that national policies necessarily involve compromise and often-imperfect reasoning, the state is capable of morally relevant and purposive action in much the same way that the adult humans are capable of regardless of their incomplete knowledge and internal tensions between conflicting values, desires, and interests (Erskine, 2003: 27). If we reflect those cognitions upon a case of vaccination, the state should have moral obligations regarding citizens' health. Primarily reason for moral agency of the state is seen in state's virtue as protector of well-being of its citizens, which include taking care of public health. Surely, vaccination is one of measures that state can perform in order to protect public health. However, vaccines as medical products have side effects that can harm or even destroy someone's health. Therefore, the state should have an obligation to develop policies that balance between protection of the public's health and possible negative side effects of vaccination. This means that the state should estimate the risk that vaccine side effects impose to the health of its citizens and vague whether they are in a case of serious side effects necessary tool in health protection. It is especially important when the risk from vaccine health impairment could be higher than risk from diseases that vaccines should initially protect, as we can see on the example of $\mathrm{H}_{1} \mathrm{~N}_{1}$ flu vaccine against pandemic swine flu in 2009. This vaccine was offered a worldwide, although it was not enough tested regarding efficiency and possible side effects on human health (MacKenzie, 2010). Declaration of swine flu pandemic encouraged states to buy vaccines against flu and promote them among its citizens (Macrea, 2010). As influenced scientists warned that a vaccine against $\mathrm{H} 1 \mathrm{~N} 1$ virus could be inefficient with serious side effects to health, states could have made morally relevant decision on its application (H1N1 Flu Is a False Pandemic, Health Expert Claims, 2010). However, many states in Europe, except Poland, decided to buy vaccines and encouraged citizens to approach to vaccination that needlessly exposed millions of healthy people to the risk of serious side effects of insufficiently tested vaccines (Macrea, 2010; Olik, 2010).

\section{Causal relevancy of vaccine health impairment}

The accepted perception is that one is morally responsible for what he causes. If one causes a bad outcome, generally, he is morally responsible for it and if one causes only part of that bad outcome; he is only responsible for the part that he causes (Bernstein, 2017). For example, if one voluntarily takes vaccine and became ill from the vaccine, he is morally responsible for all bad outcomes regarding its health. In that case, we can assume that he knew possible side effects and accepted the risk of their occurrence so he is responsible for health impairment when serious side effect occur. However, if the vaccine was mandatory and he did not have the opportunity to refuse the vaccination, the question is whether a state could be held responsible for one's health impairment that was triggered by vaccine side effects. As causation is itself a complex topic and there could be many causes of every serious vaccine injury, it is needed to examine whether there is some causal relation between the action of the state and the health impairment. That is necessary as health impairment can be attributed to state only if state played a causal role in 
bringing it about (Braham \& van Hees, 2012: 607). We will treat the actual causation question, as being determined by the counterfactual model of causation (Paul, 2012: 158). For purposes of this paper, the focus will be on the idea that there is the counterfactual dependence between mandatory vaccinations as suitably distinct event $c$ and health impairment as event $e$ that would not have occurred without it. In that case, according to Lewis' causation is the ancestral of the "causal dependence" relation, where event $e$ "depends causally" on a distinct event $c$, if $c$ and $e$ occur and if $c$ had not occurred, $e$ would not have occurred (Lewis, 1973: 562-563). If we apply this analysis in case of vaccine health injury, we may conclude that health impairment depends causally on the prescription of mandatory vaccination, as distinct event, only if health impairment would not occur in the absence of mandatory vaccination, as a person would not then be subject of vaccination.

However, when $c$ causes $e$, it does so whether or not there are other events around, assuming that these other events are not causally or otherwise necessarily connected to $c$ or $e$ (Paul, 2012: 158). This means that whether or not mandatory vaccination causes health impairment, impairment is independent of other entities not causally or otherwise connected to them.

But if some other event, such as health status before vaccination, in combination with mandatory vaccination causes health impairment, the question is whether vaccination and pre vaccination health status could be symmetrical causal contributions to impairment? According to Schaffer's notion of causation, it is possible that $c 1$ and $c 2$ could be over determining causes of $e$ (Schaffer, 2003: 23). Applied to example of vaccine health impairment, health status before vaccination (e.g. existence of a genetic predisposition for some illness) and vaccines simultaneously caused health impairment, while without them both impairment would not occur. If mandatory vaccination and health status before vaccination are taken as over determining causes of health impairment, the question is do they cause health impairment individually or collectively? (Schaffer, 2003: 24). According to Schaffer, $c 1$ and c2 could cause health impairment individually and collectively as sum (Schaffer, 2003: 24). Schaffer claims that individualism follows in a case in which "c causes $e$ if $\mathrm{O}(c) \& \mathrm{~L} \rightarrow \mathrm{O}(e)$ " (Schaffer, 2003: 25). In other words, "the conjunction of the occurrence of $c$ and the laws of nature entails the occurrence of $e$ " (Schaffer, 2003: 25). In vaccination case, it means conjunction of mandatory vaccination and genetic predisposition for some illness resulted with health impairment as they were lawfully sufficient for health impairment. On the other hand, we can speak on the collectivism when "c causes $e$ if $\sim \mathrm{O}(c)>\sim \mathrm{O}(e)$, which means that if $c$ has not occurred then $e$ would not have occurred" (Schaffer, 2003: 25). In vaccination case, it means that health impairment would not occur though one of the causes (mandatory vaccination or genetic predisposition for illness) have not been present (Schaffer, 2003: 25).

However, the problem may arise when we ask ourselves whether $e$ counterfactually depend on $c 1$, if $c 2$ also can cause $e$. The rational conclusion could be that $e$ does not counterfactually depend on $c 1$, because $c 2$ also causes it. If we want to defend counterfactual causation, it seems we are to be forced to accept one of two options - "neither $c 1$ or $c 2$ caused $e$, or the mereological sum of $c 1$ and $c 2$ caused $e$, for $e$ is counterfactually dependent on this sum“ (Paul, 2012: 176).

As it is not convincing to claim that "neither $c 1$ nor $c 2$ is a cause of $e$, we have to accept that mereological sum $c 1$ and $c 2$ seem to have cause $e$ " (Paul, 2012: 176). It means that if we observe that vaccination and genetic preconditions for illness jointly cause health impairment, we can consider that the state is responsible for impairment as it prescribed obligatory vaccination that triggered genetics illness. 


\section{Avoidability of vaccine health impairment}

The state is obliged to protect citizens' health and in that aim, it usually takes preventative measures. Sometimes preventative measures such as mandatory vaccination may result with health impairment for some citizens. In that case, we may ask ourselves whether we can hold state morally responsible for health impairment in cases that are result of measures aimed for protection of health such as mandatory vaccination. If we accept the perception that the state is only morally responsible for what it causes, the question is whether it is responsible for cases that could be avoided if the state has done something otherwise. That lead us to the idea, questioned by Frankfurt, that we can hold someone morally responsible for what he has done only if he could have done otherwise (Frankfurt, 1969: 829). It means that we could hold state morally responsible for vaccine health impairment in all those cases where state could take some measures to prevent impairment. For example, if vaccine triggers genetic predisposition for illness the state should be held responsible as it could prescribe genetic testing before vaccination. The same is applicable in cases when someone develops a serious allergic reaction after administration of the vaccine that could lead to further health problems or even death. However, vaccines are meant for a healthy population, as their aim is to enhance immunity regarding some dangerous communicable diseases that could not be prevented otherwise. Therefore, testing before vaccination is not usual, but we cannot say that the state did not have an opportunity to avoid health impairment that occurred after vaccination. In other words, it means that the state could prescribe genetic or allergy testing for all citizens that were subject of mandatory vaccination in order to determine whether citizens are healthy before vaccination. In that case we can hold state morally responsible as health impairment could be avoided by testing. However, what about moral responsibility of state in cases of vaccine health impairment where we presume that state could not have done otherwise and provide testing (Frankfurt, 1969: 829-830). For example, if there are no appropriate methods for genetic testing that could be performed in a state that prescribes mandatory vaccination for its citizens. In those cases, we may say that there were circumstances that made it impossible for a state to avoid vaccine infringement, as it was not possible to predict that genetics could trigger health impairment. If we accept that statement as a valid excuse, according to Frankfurt, it means that the state caused health impairment with mandatory vaccination without pre testing of citizen's health because it was unable to do otherwise (Frankfurt, 1969: 838). Following this argument, we may conclude that the state did not cause health impairment because it wanted harm individual that suffered impairment, yet the impairment occurred as consequence of state obligation to protect public health from communicable diseases. In other words, vaccine health impairment occurred only because the state had to prescribe mandatory vaccination to protect public health. Therefore, the state could not be held morally responsible for it as the state could not have done otherwise and avoid impairment that was caused to individual. However, the circumstances of the inability of tests could play a role in remediation of moral responsibility even when state caused health impairment because it wanted to do so. That is especially applicable to cases where the state has policy only to bring down the number of communicable deceases that affects public health and it is not interested in consequences of vaccine side effects on an individual's health. In those cases, as Frankfurt sees it, it is not correct to say that the state is morally responsible for vaccine health impairment because the state could not have done otherwise and prevent impairment even if the state wanted to provide vaccination (Frankfurt, 1969: 839).

\section{Conclusion}

Health is considered an important moral good and relevant to state policy as without health it is impossible for citizens to achieve well-being. Therefore, we may say that the state aims at enabling people to have a good health. In that manner, the state is providing measures that are aimed to enhance, preserve and protect public health. One of those measures is vaccination, which 
serves as a protective measure against transmission of communicable diseases. Although vaccination protects health, it can also have side effects that can cause health impairment to some individuals. In such cases, the question is whether we can assign the burden of moral responsibility for health impairment to the state who prescribes mandatory vaccination in order to preserve public health. In order to answer the question regarding moral responsibility of the state in case of mandatory vaccination, moral agency, causal relevancy and opportunity of avoidance were taken as preconditions for justification of a state blame. Regarding moral agency it was proposed that the state could be considered as a moral agent with "the capacity of making free choices, deliberating about what ought to do, and to understand and apply moral rules correctly" (See supra ch. 2; Himma, 2009: 24.) That means that state was seen as an agent that is able through its executive and legislative organs understand and reflect upon moral rules, as well as to act freely in a way to conform to these rules (See supra ch. 2). In case of vaccination, it means that the state should be able to estimate the risk that vaccine side effects could impose to the health of its citizens and vague whether they are in a case of serious side effects necessary tool in health protection. Further, to attribute moral responsibility to state in the case of vaccine, health impairment it was needed to examine whether causal relevancy exists between mandatory vaccination prescribed by state and health impairment. The starting point of the analysis was the Lewis's counterfactual dependence, according to which health impairment depends causally on the prescription of mandatory vaccination, as distinct event, only if health impairment would not occur in the absence of mandatory vaccination, as a person would not then be subject of vaccination. As health impairment usually appears in conjunction of mandatory vaccination and other health problems such as genetic predispositions for some health problems or allergies to some substances, it is hard to determine the causal connection between vaccination and health impairment. In order to solve that problem Schaffer's causal theory was used. According to Schaffer's notion of causation health impairment could occur if one of the causes such as mandatory vaccination or genetic predisposition to illness or allergic reaction have been present (Schaffer, 2003: 25). However, as Schaffer sees, the problem may arise when we ask ourselves whether health impairment counterfactually depends on mandatory vaccination if genetic preconditions can also cause same health impairment. The solution for this problem was seen in defending counterfactual causation by accepting that "mereological sum of mandatory vaccination and genetic preconditions caused health impairment that is counterfactually dependent on this sum (Paul, 2012: 176). In order to attribute moral responsibility to state the third condition - opportunity of avoiding - was analysed. For that purpose the rule that "someone can be held morally responsible for what he has done only if he could have done otherwise" (see supra ch. 4) was applied to vaccine health impairment case, which resulted with the conclusion that we could hold state morally responsible for vaccine health impairment in cases where state could take some measures to prevent impairment such as genetic or allergy testing. Although testing before vaccination is not usual practice, we may not say that it can exclude moral responsibility of the state in that case. Therefore, the moral responsibility would not be attributable to the state only if the state could not have done otherwise and provide testing as an example of no existence of genetic testing. However, according to Frankfurt, "one will not be morally responsible for what he has done if one did it only because he could not have done otherwise, even if what he did was something he really wanted to do"(Frankfurt, 1969: 839). If applying this rule to the case of vaccine health impairment it means that the state would not be morally responsible for vaccine health impairment because the state could not have done otherwise and prevent impairment even if the state wanted to provide vaccination. This Frankfurt's rule should be questioned, as the state should not only act as protector of public health, but as a protector of an individual's health as well. Therefore, we may hold state morally responsible for health impairments, which are result of mandatory vaccination that at the same time does not aim to protect public and individual health. In other words, it means that states could be morally responsible only if there is an existence of circumstances that made impossible to state to protect in the same time public and individual health. It could be especially 
applicable to the example when there are no available tests that could make it possible for a state to estimate risk for health impairment and avoid it in individual cases.

\section{Acknowledgements}

This research did not receive any specific grant from funding agencies in the public commercial, or not-for-profit sectors.

The author declares no competing interests.

\section{References}

Bernstein, S. (2017). Causal proportions and moral responsibility. In: D. Shoemaker (Ed.), Oxford Studies in Agency and Responsibility, 4, 165-182. Oxford: Oxford University Press. https://doi.org/10.1093/oso/9780198805601.001.0001

Braham, M. \& van Hees, M. (2012). An anatomy of moral responsibility. Mind, 121(483), 601-634. https://doi.org/10.1093/mind/fzso81

French, P. A. (1984). Collective and corporate responsibility. New York: Columbia University Press.

Erskine, T. (2003). Assigning responsibilities to institutional moral agents: The case of states and "quasistates”. In: T. Erskine (Ed.), Can Institutions Have Responsibilities? Collective Moral Agency and International Relations (19-40). New York: Palgrave Macmillan.

Fleming, S. (2017). Moral agents and legal persons: The ethics and the law of state responsibility. International Theory, 9(3), 466-489. https://doi.org/10.1017/S1752971917000100

Frankfurt, H. G. (1969). Alternate possibilities and moral responsibility. The Journal of Philosophy, 66(23), 829-839. Retrieved from https://www.jstor.org/stable/2023833.

Goodin, R. E. (1995). Utilitarianism as a public philosophy. New York: Cambridge University Press.

Greenwood, B. (2014). The contribution of vaccination to global health: Past, present and future. $\begin{array}{lllll}\text { Philosophical Transactions of Royal Society, } & 369(1645), & \text { 1-19. }\end{array}$ https://doi.org/10.1098/rstb.2013.0433

Himma, K. E. (2009). Artificial agency, consciousness, and the criteria for moral agency: what properties must an artificial agent have to be a moral agent? Ethics and Information Technology, 11(1), 19-29. https://doi.org/10.1007/s10676-008-9167-5

Jefferson, T. (1998). Vaccination and its adverse effects: real or perceived. Society should think about means of linking exposure to potential long-term effect. British Medical Journal, 317(7152), 159-160. Retrieved from https://www.ncbi.nlm.nih.gov/pmc/articles/PMC1113535/.

Kingston, L. N., Cohen, E. F., \& Morley, C. P. (2010). Debate: Limitations on universality. The "right to health" and the necessity of legal nationality. BMC International Health and Human Rights, 10(11), 1-12. https://doi.org/10.1186/1472-698X-10-11

Lammer-Heindel, C. S. (2012). Does the state have moral duties? State duty-claims and the possibility of institutionally held moral obligations (Doctoral dissertation, University of Iowa). Retrieved from http://ir.uiowa.edu/etd/3330.

Lawford-Smith, H., \& Collins, S. (2017). Responsibility for states' actions: Normative issues at the intersection of collective agency and state responsibility. Philosophy Compass, 12(11), 1-8. https://doi.org/10.1111/phc3.12456 
Lewis, D. (1973). Causation - Seventieth Annual Meeting of the American Philosophical Association Eastern Division. The Journal of Philosophy, 7o(17), 562-563. https://doi.org/10.2307/2025310

Miller, D. (2007). National responsibility and global justice. Oxford: Oxford University Press.

O'Neill, O. (1986). Who can endeavour peace? Canadian Journal of Philosophy, 16(1), 41-73. https://doi.org/10.1080/00455091.1986.10717154

Paul, L. A. (2012). Counterfactual theories. In: H. Beebee, C. Hitchcock \& P. Menzies (Eds.), The Oxford handbook of causation (158-185). Oxford: Oxford University Press.

Ripstein, A. (2001). Equality, responsibility and the law, Cambridge: Cambridge University Press.

Schaffer, J. (2003). Overdeterminig causes. Philosophical Studies, 114(1-2), 23-45. https://doi.org/10.1023/A:1024457117218

Schramme, T. (2009). On Norman Daniels' interpretation of the moral significance of healthcare. Journal of Medicine Ethics, 35(1), 17-20. https://doi.org/10.1136/jme.2008.024208

Schwenkenbecher, A. (2011). Moral obligation of state. In center for applied ethics and philosophy (Ed.), Applied Ethics: Old Wine in New Bottles, (86-94). Hokkaido University, Sapporo, Japan. Retrieved from https://philpapers.org/archive/SCHAES-2.pdf.

\section{Legislation}

UN General Assembly, Universal Declaration of Human Rights, 10 December 1948, 217 A (III). Retrieved from http://www.refworld.org/docid/3ae6b3712c.html.

UN Educational, Scientific and Cultural Organisation (UNESCO), Universal Declaration on the Human Genome and Human Rights, 11 November 1997. Retrieved from http://www.refworld.org/docid/404226144.html.

UN General Assembly, International Covenant on Economic, Social and Cultural Rights, 16 December 1966, United Nations, Treaty Series, vol. 993, p. 3. Retrieved from http://www.refworld.org/docid/3ae6b36co.html.

\section{Internet pages}

H1N1 Flu Is a False Pandemic, Health Expert Claims. (2010). Retrieved 30 May 2018, from http://www.foxnews.com/story/2010/01/11/h1n1-flu-is-false-pandemic-health-expertclaims.html.

MacKenzie, D. (2010, January 11). Vaccine for swine flu pandemic was 'morally justified'. Retrieved from https://www.newscientist.com/article/dn18381-vaccine-for-swine-flu-pandemic-wasmorally-justified/.

Macrea, F. (2010, January 18). The 'false' pandemic: Drug firms cashed in on scare over swine flu, claims Euro health chief. Retrieved from http://www.dailymail.co.uk/news/article-1242147/Thefalse-pandemic-Drg-firms-cashed-scare-swine-flu-claims-Euro-healthchief.html\#ixzz5Gvtak4XG.

Olik, M. (2009, November 15). Poland and the H1N1 Flu: Calm and Unvaccinated. Retrieved from https://www.globalresearch.ca/poland-and-the-h1n1-flu-calm-and-unvaccinated/16109. 